\title{
Characterizing the temporal and spatial variability of African dust over the Atlantic
}

\author{
Joseph M. Prospero
}

\begin{abstract}
Mineral dust in sediments and ice cores is often used as a proxy for changes in aridity and large-scale wind systems. Long-term dust measurements on Barbados and other Atlantic sites show a close but complex relationship between hydroclimate and dustiness.
\end{abstract}

\begin{abstract}
Mineral dust plays a role in many aspects of climate through atmospheric processes by absorbing and scattering solar radiation and by impacting cloud microphysical processes (Shao et al. 2011). Also, dust deposited to the ocean yields nutrients that can modulate marine biogeochemical processes and the global carbon cycle and, hence, climate (Shao et al. 2011). The climate-dust relationship is complicated by the fact that dust generation and transport are themselves modulated by climate.
\end{abstract}

Dust records in sediments and ice cores show that transport has varied greatly over glacial-interglacial (Maher et al. 2010) and shorter timescales. In order to use dust as a proxy in paleoclimate studies, we need to understand the role that climate plays in modulating dust transport today. This information is also important to understanding how dust can itself affect climate. Here we present the results of long-term network studies in the North Atlantic that characterize the great variability in transport over the region. These studies yield insights into some of these processes that affect variability and give direction for further research on the link to climate.

\section{The Barbados record}

North Africa is the focus of much dust research because it is the world's largest persistently active source, accounting for about $70 \%$ of total dust emissions (Huneeus et al. 2011). Much of this dust is carried to the west over the Atlantic in large-scale plumes, some of which can be tracked by satellites all the way to the southern United States (Bozlaker et al. 2013), the Caribbean and South America (Chin et al. 2014; Yu et al. 2013).

Our understanding of long-term trends in dust transport to these regions rests largely

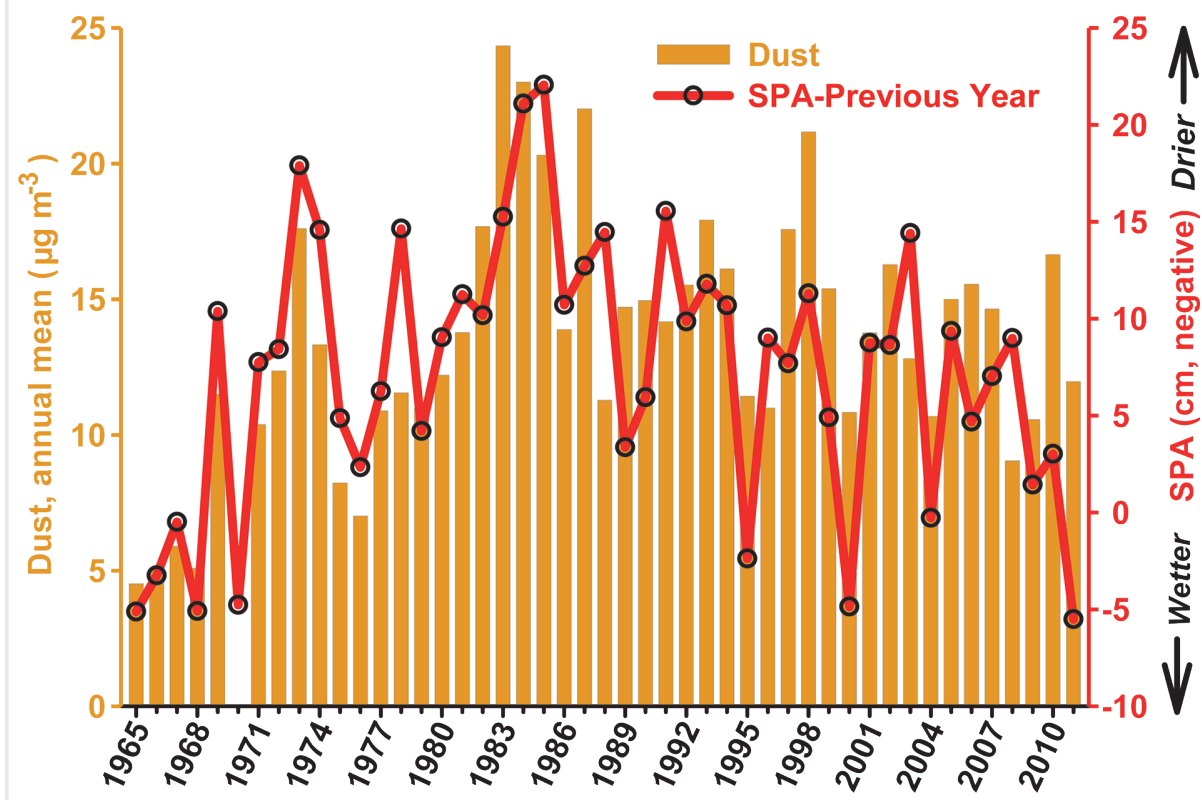

Figure 1: Barbados annual mean dust concentrations and Sahel June-October Precipitation Anomalies (SPA) from 1965-2011. To more easily compare dust concentrations with rainfall metrics, the SPA values are plotted as the arithmetic negative. SPA data are taken from www.jisao.washington.edu/data_sets/sahel/ with anomalies calculated from data over the period 1950 to 2011 on aerosol monitoring studies on Barbados that began in 1965 (Delany et al. 1967; Prospero and Lamb 2003) and which continue to this day at the University of Miami atmospheric chemistry field site located on the east coast of Barbados $\left(13.17^{\circ} \mathrm{N}\right.$; $59.43^{\circ} \mathrm{W}$; Prospero and Mayol-Bracero 2013).

Barbados dust concentrations show great variability on a broad range of time scales ranging from days, to seasons, to decades (Prospero and Lamb 2003). Of particular interest is the long-term variability seen in the annual mean concentrations over 1965-2011 (Fig. 1). Dust transport increased sharply in the early 1970s with the onset of severe longterm drought in West Africa and peaked in the mid-1980s coincident with the most intense phase of the drought.

This increase focused attention on the role of rainfall in the dust cycle particularly in the Sahel, a region that depends greatly on the seasonal progression of the West African monsoon to provide rainfall (Marticorena et al. 2010; Doherty et al. 2012). In the first half of the record, increased transport is clearly associated with markedly drier conditions in the Sahel as seen in the close relationship between rainfall variations (expressed as Sahel Precipitation Anomalies; SPA) and dust concentration (Fig. 1). SPA is based on precipitation departures from the mean over the period 1950-2011. This association fits our general expectation that drier climate results in dustier conditions.

However, beginning in the early 1990s, this relationship appears to weaken. Dust concentrations remain relatively high despite increased rainfall and evidence of "greening" in the Sahel (de Jong et al. 2011). Although there is considerable year-to-year variability in dust transport and rainfall there is no strong relationship between the two. Note, for example, that dust concentrations in 1987, 1997-1998, and 2010 were comparable to those at the peak of the drought; in contrast, the SPAs, although moderately positive (i.e. relatively dry) were generally closer to the long-term mean. It is notable that over the period 1989 to 2005 most SPA annual means fall within a narrow range and show no evidence of a trend. However, after 


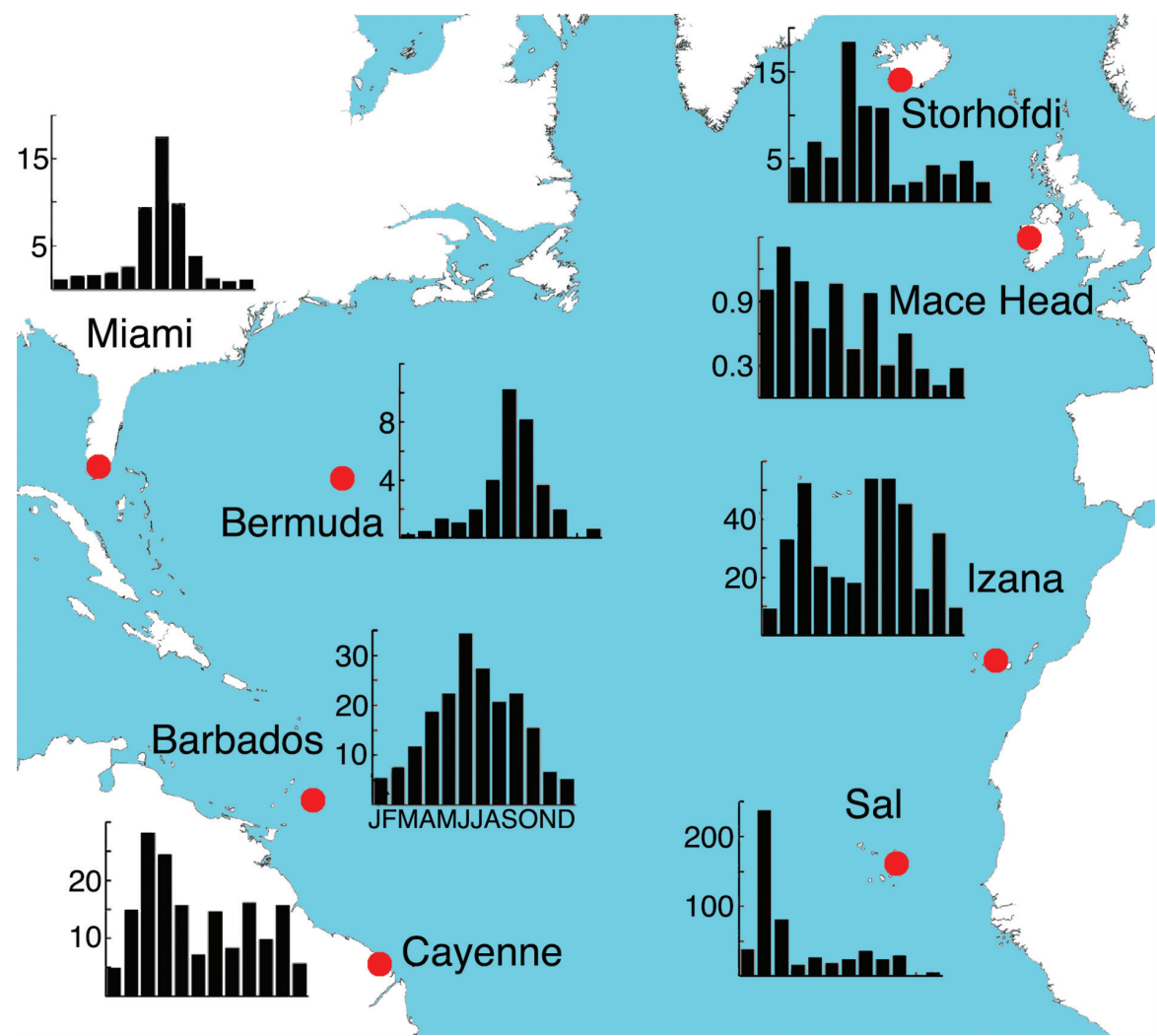

Figure 2: The annual cycles of monthly mean dust concentrations at University of Miami network sites in the North Atlantic. The means at each site are based on multi-year data but they are not necessarily measured concurrently. Note the difference in the ordinate scales in each inset figure. Figure adapted from Prospero et al. (2012).

2007 rainfall was close to normal yet dust concentrations remain moderately high, especially in 2010.

\section{Dust transport to South America}

The annual mean values on Barbados (Fig. 1) are strongly weighted by the high dust concentrations that prevail during boreal summers. Although dust concentrations are low in winter and spring on Barbados, we know that there is intense dust activity in North Africa in the Sahel region, most prominently in the Bodele Depression in northern Chad (Ben-Ami et al. 2012). Bodele sediments, deposited during the Holocene in what was Lake Mega Chad, are now being mobilized in huge quantities (Washington et al. 2009). Almost daily in spring, satellites show immense plumes being carried westward across the Atlantic, many eventually reaching South America in the region of French Guiana, $8000 \mathrm{~km}$ from the source. Ten years of recent air-quality aerosol measurements from Cayenne, a coastal town in French Guiana $\left(04.95^{\circ} \mathrm{N} ; 52.31^{\circ} \mathrm{W}\right)$, show a strong annual cycle with a spring maximum (Prospero et al. 2014). The magnitude and persistence of dust transport has had a significant impact on the supply of minerals and nutrients to the soils and sediments to the Caribbean and South America (including the Amazon; Ben-Ami et al. 2012; Muhs et al. 2007) and to the tropical and subtropical Atlantic (Baker et al. 2013).

\section{Dust transport to the North Atlantic}

The Barbados and Cayenne measurements and those made at other sites in the Miami Atlantic network (Fig. 2) document the widespread impact of mineral dust over the North Atlantic. Dust concentrations at all sites except Mace Head (Ireland) and Storhofdi (Iceland) are dominated by African dust, most notably in the subtropical and tropical regions. Iceland dust is transported by winds from paraglacial deposits in southeast Iceland and deposited to the North Atlantic where it might serve as an important source of nutrient iron (Prospero et al. 2012).

The summer maximum observed at Barbados, Miami, and Bermuda contrasts greatly with the spring maximum at Cayenne, which reflects the combined effects of the seasonal shifts in African dust sources and in the transporting wind systems. The records closest to Africa at Izaña (Tenerife) and Sal Island (Cape Verde Islands) differ greatly in seasonality and in concentrations from those observed at the western sites (Fig. 2). This contrast shows that dust transport processes to the eastern Atlantic differ from those that carry dust to the western Atlantic (Stuut et al. 2005) and complicates attempts to relate the composition of sediments in the eastern Atlantic to the more westerly regions.

In order to more fully understand the various factors affecting dust mobilization we need a better understanding of the most active source areas (Prospero et al. 2002), the factors affecting source activity (Formenti et al. 2011; Ginoux et al. 2012) and the relationship between source soil properties and those of the emitted aerosol, such as particle size (Mahowald et al. in press) and composition (Scheuvens et al. 2013). This knowledge is important to interpreting dust-climate relationships and decoding the paleo-dust records from sediments and ice cores.

\section{Understanding dust and climate}

While rainfall is a critically important factor for dust emission, we know that other factors also play a role (Okin et al. 2011), most notably wind speed and gustiness (Ridley et al. 2014) and terrain features, especially vegetation cover (Bullard et al. 2011). In the future, land use and land disturbance will become increasingly important (Ginoux et al. 2012) as populations shift and grow. The complexity of these relationships presents a challenge to the modeling community (Huneeus et al. 2011).

Africa, as the world's largest present-day dust source, presents a special challenge when anticipating the changes in dust emissions in coming decades. It is notable that in the recent IPCC assessment, models forecast that large areas of North Africa will become drier (Seneviratne et al. 2012). However, the models could not agree on the future trends in large areas of North Africa that today are the most active dust sources, most notably those in the Sahara and the Sahel. Thus, it is important that we continue to monitor transport from Africa to the Atlantic in a systematic manner so as to track changes over this region and to test the ability of dust-climate models to characterize long-range transport to the oceans (Schulz et al. 2012).

\section{ACKNOWLEDGEMENTS}

This research is supported in part by NSF Atmospheric Chemistry grant AGS-0962256.

\section{AFFILIATIONS}

${ }^{1}$ Rosenstiel School of Marine and Atmospheric Science, University of Miami, USA

\section{CONTACT}

Joseph M. Prospero: jprospero@rsmas.miami.edu

\section{REFERENCES}

Full reference list under:

www.pages-igbp.org/products/magazine/ref2014_2.pdf

Ben-Ami Y et al. (2012) Atmos Chem Phys 12(5): 2253-2262

Huneeus N et al. (2011) Atmos Chem Phys 11(15) 7781-7816

Prospero JM, Lamb PJ (2003) Science 302: 1024-1027

Prospero JM, Mayol-Bracero OL (2013) Bull Am Meteorol Soc 94: 1329-1337

Prospero J M et al. (2014) Global Biogeochem Cycles 28: 757-773

Prospero JM et al. (2012) Science 335: 1078-1082 